Article

\title{
Gender Difference in the Influence of Family Interaction and Parenting Behaviours on Youth Sexual Intention
}

\author{
Noor Azimah Muhammad ${ }^{1, *}$, Hizlinda Tohid ${ }^{1}$, Khairani Omar ${ }^{1}$, Rahmah Mohd. Amin ${ }^{2}$ \\ and Khadijah Shamsuddin ${ }^{3}$ \\ 1 Department of Family Medicine, Faculty of Medicine, Universiti Kebangsaan Malaysia, Jalan Yaacob Latiff, \\ Cheras, Kuala Lumpur 56000, Malaysia; hizlinda@ppukm.ukm.edu.my (H.T.); khairanio@gmail.com (K.O.) \\ 2 Faculty of Medicine and Health Sciences, Universiti Sultan Zainal Abidin (UniSZA), Medical Campus, \\ Jalan Sultan Mahmud, Kuala Terengganu, Terengganu 20400, Malaysia; rahmahamin@unisza.edu.my \\ 3 Department of Community Health, Faculty of Medicine, Universiti Kebangsaan Malaysia, \\ Jalan Yaacob Latiff, Cheras, Kuala Lumpur 56000, Malaysia; khadijah@ppukm.ukm.edu.my \\ * Correspondence: drazimah@ppukm.ukm.edu.my or drazimah@gmail.com
}

Received: 16 June 2017; Accepted: 31 August 2017; Published: 5 September 2017

\begin{abstract}
This paper presents the differences in family interaction and parenting behaviours and their influence on sexual intention among male and female youths aged 18 to 22 years. The results presented are based on data collected from unmarried college students in Klang Valley, Malaysia. Despite being in a country where premarital sexual activity is not an accepted behaviour, $18 \%$ of the 422 male and $1.4 \%$ of the 566 female students indicated their intention to perform sexual activity. Compared to females, males had more allowance of autonomy from parents and lesser parental monitoring, paternal care, parent-youth communication on sexual issues, and family connectedness. Both genders perceived that they received similar levels of parental control. In male youths, having high maternal control (OR: 1.19, 95\% CI: 1.03-1.38) and family modelling behaviour (OR: 2.25, 95\% CI: 1.19-4.25) increased their odds of having sexual intention while having high parent-youth communication on sex (OR: 0.89, 95\% CI: 0.81-0.99) reduced their odds of having sexual intention. For female youths, having a high level of family connectedness (OR: 0.76, 95\% CI: 0.59-0.97) was a protective factor against sexual intention. In conclusion, sexual intention is higher among males compared to females. The influence of family interaction and parenting behaviours on youth sexual decision varied across gender. This study highlighted the possibility of using different parenting approaches in tackling premarital sexual activity among youths.
\end{abstract}

Keywords: gender; young people; parenting; family connectedness; communication; modelling behaviours; sexual intention

\section{Introduction}

Over the years, youth sexuality has drawn the attention of many health care professionals and scientists, mainly because of its related complications such as sexually transmitted diseases and unwanted pregnancies. In recent years, research on youth sexuality has also looked into intimate relationships and sexuality as part of the normal sexual development in youths (Boislard et al. 2016). However, with a collectivist culture, like those in Asian and Arab countries, that emphasises social responsibility and relationships (Boislard et al. 2016), the idea of unmarried youths practicing sexual activity as part of their normal growing process is not well accepted. Malaysia is a conservative country that opposes premarital sexual activity, and under Malaysian law, marriage is only allowed when youths reach 18 years of age. Unfortunately, despite disapproval by society, premarital sexual activity 
does occur among our young people. The prevalence of premarital sexual activity among school-age children aged 12 to 17 years old was $8.3 \%$, and half of these youths had their sexual debut earlier than 14 years old (Ahmad et al. 2014). The prevalence is expected to be higher as the age of the youths increases. The reported prevalence of premarital sexual activity among high school students aged 15 to 20 years old was 13\% (Anwar et al. 2010). Risky sexual activities were also prevalent among our sexually active youths; $60 \%$ to $70 \%$ of them were not using contraception and $20 \%$ to $30 \%$ had multiple sexual partners (Ahmad et al. 2014; Manaf et al. 2014; Ahmadian et al. 2014). Since most of their sexual activities are done secretly and against the social norms or expectation, they need to plan their activities ahead.

As described by the Theory of Planned Behaviour, in a situation when a person has full control, intention is the most proximal determinant of a behaviour (Ajzen 2011). In the context of sexual activity, sexual intention refers to a person's desire and plan to perform sexual activity and based on the theory, sexual intention precedes sexual activity. The prevalence of youths with sexual intention is found to be correlated closely with the prevalence of youth sexual activity. This positive relationship was shown in a study among Latino youths, where the intention to perform sexual intercourse in the next three months was positively correlated $(r=0.41)$ with youth sexual activity in the last three months (Villarruel et al. 2004). A review of 69 studies conducted in the US from 1996 to 2005 showed that sexual intention was the most stable predictor of youth sexual activity (Buhi and Goodson 2007). In countries which are more permissive towards the practice of premarital sex, the prevalence of sexual intention among youths is expected to be high. This was shown in a US study involving youths aged 12 to 17 years, in which the prevalence of youths with sexual intention within the next year was 64\% (Carmack and Lewis-Moss 2009). In contrast, the prevalence is expected to be lower in countries with a conservative attitude towards premarital sex, as shown in studies among Indonesian and Iranian youths. In a study involving high school students in Indonesia, less than $10 \%$ of the youths declared their plan of not staying abstinent until marriage (Leerlooijer et al. 2014), while a study among Iranian male high school students found that $23 \%$ expressed their intention not to stay abstinent (Mohtasham et al. 2009).

Many countries including the US, Swaziland, Australia, Vietnam, Taiwan, and China have documented the male predominant pattern in youth sexual activity (Deardorff et al. 2010; Sacolo et al. 2013; Vuttanont et al. 2006; Zuo et al. 2012; Siebold 2011). Females are expected to preserve their virginity until marriage, while males are more likely to experience sexual freedom. Popular reasons include the risk of pregnancy and the responsibility of childcare face by females, while there are no obvious biological changes in sexually active males. This sexual double standard persists to date, and this gender difference is partly contributed by cultural and socialisation factors (Boislard et al. 2016). A qualitative study conducted among college students aged 18 to 23 years in the US described the expected role of males and females in a sexual relationship. Males were viewed as sexual initiators while females as a 'gatekeeper'. Female youths were passive in a sexual relationship; they would agree to sex when asked, were less likely to make sexual requests, and satisfying sexual needs was not their main priority (Jozkowski and Peterson 2013). Similarly, youth sexual intention is expected to be different between genders. This was observed among South African youths, in which the prevalence of male youths aged 13 years with sexual intention was $26 \%$ while that of female youths was $14 \%$ (Mathews et al. 2009).

Apart from the Theory of Planned Behaviour, the Ecological System Theory has also been used to understand human behaviour. This theory posits that a person's behaviour is influenced by frequent interaction between the person and the people in the environment such as family, friends, and people in the community (Sallis et al. 2008). Parents are the closest and most immediate individuals in one's life from whom children learn about cultural and moral values, beliefs, and ethics on what is allowed and not allowed with regards to sexuality (Kotchick et al. 2001). Family interaction involves verbal and non-verbal communication that includes family connectedness, parent-youth communication, and family modelling behaviour. According to Barnes and Olson (1985), communication strikes a balance between separateness and cohesion. It helps family members to be connected to each other while 
maintaining some privacy between them. Families with good parent-youth communication tend to have a close relationship, adaptability, and satisfaction among the members (Barnes and Olson 1985). Family connectedness is defined as the closeness, warmth, and support among family members (Markham et al. 2003). Those who feel connected with their families will feel that there are family members who care for them and will be available to support them whenever they have problems. They will turn to their families for guidance and support, and this is important during youth development as this will make them feel safe and secure (Lee and Lok 2012).

With regards to specific parent-youth communication on sex, parents and youths may discuss sexual issues pertaining to sexual reproductive health that include general information about sex, safe sex, and consequences of sexual activity such as sexually transmitted diseases, pregnancy, and abortion. Parental attitude towards premarital sex and knowledge of sexual reproductive health will influence the topic discuss between them (Afifi et al. 2008). Parents with a conservative attitude or those with limited knowledge may avoid discussing the issues in detail. They tend to focus more on moral perspectives and the common physical changes that may happen in sexually active youths. Each family is unique and its members follow certain standards of acceptable behaviour or family norms defined by them, especially parents (Deković and Buist 2005). Often, older family members will be the role model for the younger ones. Through observation, children form normative beliefs and copy their family behaviours.

Parenting behaviours can be classified into four types; authoritarian, authoritative, permissive, and neglectful, depending on the level of parental responsiveness and demandingness (Baumrind 2005; Steinberg 2014). Authoritarian parenting denotes a high level of demandingness with little responsiveness. Parents are typically very controlling, rigid, and do not allow autonomy in the children. This is the typical parenting behaviour practiced by Asians including Malaysian parents in which children are expected to show obedience, cooperation, and dependence, especially to their parents (Keshavarz and Baharudin 2009). Authoritative parenting is a combination of high demandingness and responsiveness. Authoritative parents are demanding and controlling yet they are responsive and caring. They monitor their children's activities but they also allow their children to practice autonomy and be involved in decision-making. This parenting behaviour promotes independence and high self-esteem in children (Baumrind 2005; Steinberg 2014). A recent study conducted in Selangor, Malaysia involving school students aged 14 to 16 years showed a positive impact of authoritative parenting on youth development. Youths who had experienced authoritative parenting were found to be caring, competent, and confident. They had good relationships with others and possessed high integrity (Kiadarbandsari et al. 2016). Permissive parenting refers to a high level of responsiveness with a low level of demandingness. Children tend to get what they want without much restriction from their parents. Neglectful parenting is when there is a low level of both demandingness and responsiveness. Children have freedom to decide on their activities and they seem to be detached from their parents. Notably, parenting style changes with time and parents tend to be less demanding and controlling as the children grow (Wang et al. 2011).

As for the relationship between parenting and youth sexual activity, a longitudinal study among rural African American male youths showed that the lack of parental care or harsh and inconsistent parenting during childhood was associated with higher odds for risky sexual activities in these youths. Their risky sexual activities were found to persist into young adulthood (Murry et al. 2013). Two other studies conducted in the US and UK showed similar findings, where parental care or support significantly protected youths from being sexually active or involved in risky sexual activities (Rodgers and McGuire 2012; Parkes et al. 2011). Furthermore, an interventional study in rural Uganda showed that an improvement in family support was able to encourage open communication between youth and their family members, leading to positive attitude towards safe sex and thus a reduction in risky sexual activities among the youths (Ismayilova et al. 2012). In terms of family modelling behaviour, parents who exposed their frequent dating behaviours, affection, and sexual activity to their children were likely to have children with similar behaviours (Gullota 2008). In brief, family 
interaction and parenting behaviours may affect youth sexual conduct through modelling behaviour, restriction and rules, guidance, and communication. Evidence also shows that parents practice different parenting styles on their daughters and sons. In a study among Arab youths, parents were found to place stricter rules and practice a more authoritarian style of parenting on sons compared to daughters (Dwairy et al. 2006). Similarly, a study among college students in Kuala Lumpur, Malaysia showed that female youths experienced closer bonding and better relationships with their parents than male youths (Tam et al. 2012).

Due to the possibility of different family interaction and parenting styles between male and female youths, the impacts of these family factors on youth sexual intention may be different as well. On the other hand, as most youths are expected to have reached some level of cognitive maturity by the age of 18 years, their behaviours including sexual activity may not entirely be dependent on their parents. Thus far, there is no published study conducted in Malaysia that examine this gender difference. It was hypothesised that our youths would not be very much different from youths of other countries; more males than females were expected to declare their sexual intention despite living in a conservative community. Males are risk takers and adventurous. However, due to the fact that our youths were from a collectivist culture in which people are interconnected and dependent on one another, the influence of family on youth decision for sexual activity may be different from youths of individualistic cultures. Thus, this paper aimed to compare the family interaction and parenting behaviours experienced by male and female students studying in colleges around Klang Valley, Malaysia, and determine the association between these factors and their intention to engage in sexual activity according to gender.

\section{Methodology}

The data for this study was extracted from a larger study on youth sexual activity. The sample population involved students from colleges in urban Klang Valley, Malaysia. It covers Petaling, Klang, Gombak, and Hulu Langat districts as well as Kuala Lumpur, the capital city of Malaysia. This study focused on colleges in Klang Valley only, as it is the center of education for Malaysian school leavers. During the time of data collection, there were 167 colleges registered under the Ministry of Education and, using a computer-generated random number, 12 colleges were selected from the list. The principals or administrators of the respective colleges were contacted, briefed, and invited to participate in the study. A total of 26 colleges were contacted and 12 colleges agreed to participate. These 12 colleges were sufficient to provide a total sample of 1200 students with the power of study of $80 \%$, absolute precision of $5 \%$, and design effect of 2 . In order to minimise disruption in academic activities, the college administrators or principals would then select a class of students that fulfilled the study criteria, that included unmarried students and Malaysian citizens. The age range was set at 18 to 22 years as this was the age of most college students. In Malaysia, most students complete their high school at 17 years of age and subsequently enroll in colleges.

The main researcher conducted the data collection, which was carried out before or after the students' classes on different days for all of the selected colleges. The students were briefed on the study procedure and allowed to clarify any doubt before obtaining their informed consent. Students who were absent during data collection or refused to give consent were excluded, while those who agreed to participate were requested to complete a set of self-administered, anonymous questionnaires. In total, 1210 students were approached and 133 refused to participate. About 40 to 200 students were recruited from each college depending on the total number of students per college; more students were recruited from colleges with a high number of students compared to colleges with a low number of students. In some colleges, all of the students approached agreed to participate, while in others, about $10 \%$ to $20 \%$ of students declined to participate.

For the purpose of this paper, data on youth sexual intention, family interaction, and parenting behaviours were extracted for analysis. Youth sexual intention was assessed using five items with a four-point Likert scale; 1 = strongly disagree, 2 = disagree, $3=$ agree, and $4=$ strongly agree. The items covered youth expectation, planning, intention, and wanting for sexual activity with his or her partner. 
These items were part of the Youth Sexual Intention Questionnaire (YSI-Q), which had been locally developed and validated (Muhammad et al. 2017). The internal reliability, Cronbach's alpha for this scale was 0.93 . The total score for this scale ranged from 5 to 20, and a higher score indicated a higher intention to perform sexual activity. If the mean total score was 3 or above, falling on agree or strongly agree on the Likert scale, the respondents would be classified as having sexual intention, whereas if the mean total score was less than 3, falling on disagree to strongly disagree on the Likert scale, the respondents were classified as having no sexual intention.

Family interaction covered family connectedness, parent-youth communication on sex, and family modelling behaviour. The family connectedness was adapted from the Family Connectedness Scale developed by Blum and Ireland (2004); it assessed respondents' feelings about their relationship with parents and other family members. The internal reliability, Cronbach's alpha of the scale was 0.74 . The scale had five items with five-point Likert scale ranging from 1 (never) to 5 (always). The items assessed how frequently the respondents felt they received attention, care, and understanding as well as how frequently they were able to share problems with parents or other family members. The total score for this scale ranged from 5 to 25 , and a higher score indicated a higher level of family connectedness experienced by the youths. Parent-youth communication on sex was adapted from the Parent-Adolescent Communication Scale developed by Sales et al. (2008). It assessed how frequently parents and youths discussed sexual issues such as pregnancy, contraception, and sexually transmitted diseases. The internal reliability, Cronbach's alpha of the scale was 0.90 . The scale had five items with a five-point Likert scale ranging from 1 (never) to 5 (always). The total score ranged from 5 to 25 , and a higher score indicated a higher frequency of parent-youth communication on sex. The family modelling behaviour scale which was developed for the purpose of this study assessed respondents' awareness of their parents' or siblings' premarital sexual activity and if their unmarried sibling was pregnant or had made a girl pregnant, using four items with a five-point Likert scale ranging from 1 (not at all aware) to 5 (extremely aware). If respondents chose slightly aware, somewhat aware, moderately aware, or extremely aware for any of the four items, they were classified as having family modelling behaviour, and if they answered not at all aware to all items, they were classified as not having family modelling behaviour. The internal reliability, Cronbach's alpha of the scale was 0.90 .

Parenting behaviours covered parental care, control, allowance of autonomy, and monitoring. The Parental Bonding Instrument (PBI) developed by Parker, Tupling, and Brown (Parker et al. 1979) containing 25 items was designed to measure parental care and overprotection or controlling behaviour. This questionnaire was translated into the Malay language and tested on 248 college students. Based on this study, the Malay version of the Parental Bonding Instrument (PBI-M) was found to have three factor structures, namely, parental care, control, and allowance of autonomy, from which five items were removed (Muhammad et al. 2014). The PBI-M thus contained 20 items with a four-point Likert scale ranging from 1 (very unlike) to 4 (very like). There were 10 items on parental care where the total score ranged from 10 to 40 , five items on parental control where the total score ranged from 5 to 20, and five items on parental allowance of autonomy where the total score ranged from 5 to 20 . Father and mother parenting behaviours were assessed separately, and thus a higher total score of each scale indicated a higher level of paternal or maternal care, control, and allowance of autonomy, respectively. In addition, a parental monitoring scale was developed for the purpose of this study. This scale assessed how much parents monitor and know the students' activities when they were not at home. These questions were important as many of the respondents were expected to be out of their home in order to further their studies. The parental monitoring scale contained four items with a five-point Likert scale ranging from 1 (never) to 5 (always). The total score ranged from 4 to 20, and a higher score indicated a higher level of parental monitoring experienced by the respondents. A combination of the PBI-M and the parental monitoring scales would allow researchers to gauge the level of parental care, control, allowance of autonomy, and monitoring behaviours experienced by the youths. All of these family interaction and parenting behaviours had been pre-tested before their use in this study. The internal reliability, Cronbach's alpha for each scale ranged from 0.60 to 0.90 . 
Data were analysed using IBM SPSS version 20.0. Descriptive results were presented in frequency and percentage, while multiple logistic regression analysis with the enter method was used to determine the significantly associated factors for youth sexual intention. This study received institutional ethical approval as well as permission to conduct the study on college students from the Ministry of Education and the respective principal or administrator of each selected college. Respondents of this study were briefed on the study protocol and were given the option to withdraw at any point of this study. Only those who had agreed to participate were given the self-administered, anonymous questionnaire.

\section{Results}

In total, 1077 youths aged 18 to 22 years agreed to participate, but only 988 responses were used for statistical analysis. Data from $38(3.7 \%)$ youths were not included in the analysis due to incomplete responses. From the 988 respondents, 566 (57.3\%) were female students with a mean age of $19.8 \pm 1.2$ years and $422(42.7 \%)$ were male students with a mean age of $19.5 \pm 1.2$ years. As expected, female students were slightly overrepresented because, as is common in Malaysia nowadays, more females than males are pursuing their study at colleges or universities. More than half of the students $(56.3 \%)$ were from private colleges and $43.7 \%$ of them were from public colleges. More than half of them were living away from home $(65.0 \%)$, such as in a hostel or in rented houses with friends. Malays contributed more than half of the respondents (62.8\%), followed by Chinese (27.3\%), Indians $(8.1 \%)$, and others such as indigenous people from Sabah or Sarawak (1.8\%). The proportion of Malays, Chinese, and Indians closely matched the ethnic proportion in Malaysia, where Malays and indigenous people of Sabah and Sarawak form the majority and contribute $67 \%$ of the population, followed with Chinese at 25\%, Indians at 7\%, and others at 1\% (Department of Statistics Malaysia 2016). In general, the total monthly family income was divided into two groups: (1) the low income group with families earning less than RM5000 or about USD1166 a month, and (2) the high income group with families earning RM5000 or USD1166 a month or more. Based on this, most of the youths were from the low income group with a median monthly family income of RM3000 (IQR RM1500-5000) or USD699 (IQR USD 349-1166). In Malaysia, primary school is for children aged 7 to 12 years and secondary school is for children aged 13 to 17 years. Following this, students will further their study in tertiary education at colleges in order to pursue a foundation study, diploma, or degree. As declared by the students, only a third $(30.0 \%)$ of either their fathers or mothers had tertiary education. A majority of them came from intact families in which parents remained married $(90.8 \%)$ and most were from small families of less than six people $(73.2 \%)$.

Table 1 presents the mean score for parenting behaviour and family interaction variables as reported by the youths. As shown in the table, mothers seem to play a higher role compared to fathers in almost all domains of parenting behaviours which include care, control, and allowance of autonomy. Based on the mean total score, the youths reported high levels of parental care of 31 to 33 (possible range: 10 to 40), parental monitoring of 15 (possible range: 5 to 20) and family connectedness of 20 (possible range: 5 to 25). The youths reported moderate levels of parental allowance of autonomy of 14 (possible range: 5 to 20) and parental control of 12 (possible range: 5 to 20). The parent youth communication on sex was low at 7 (possible range: 5 to 25). Almost a quarter of the youths were classified as having family modelling behaviours, indicating that at least one of their family members had practiced premarital sex.

There were significant differences in the level of parenting behaviours reported by the male and female youths. Table 2 presents the result of bivariate analysis of the family interaction and parenting behaviours experienced by the youths according to gender. Female youths reported experiencing higher parenting and family interaction compared to male youths. Female youths were found to receive a significantly higher level of paternal care $(t=2.07, p=0.04)$ and parental monitoring $(t=5.86, p<0.001)$ compared to male youths. Female youths also experienced a higher level of family connectedness $(t=3.65, p \leq 0.001)$ and parent-youth communication on $\operatorname{sex}(t=4.39, p \leq 0.001)$ than 
the male youths. For the family modelling behaviours, more females (26.5\%) were aware of their family members' premarital sexual activity $\left(\chi^{2}=8.22, p<0.01\right)$ compared to males $(18.7 \%)$. Mothers were also reported to provide a higher level of care to the female youths compared to male youths, however, this was not statistically significant $(t=1.92, p=0.06)$. In contrast, male youths seemed to experience higher freedom than female youths, as there was a significantly higher level of parental allowance of autonomy reported by the male youths compared to female youths $(t=3.72, p \leq 0.001$ for mothers and $t=4.88, p \leq 0.001$ for fathers). However, parents appeared to place similar levels of controlling behaviours on their youths and there was no significant difference in the level of parental control $(t=1.36, p=0.17$ for mothers and, $t=0.69, p=0.49$ for fathers) between male and female youths.

Table 1. The level of parenting behaviour and family interaction experienced by the youths.

\begin{tabular}{lcc}
\hline \multicolumn{1}{c}{ Parenting and Family Interaction } & \multicolumn{2}{c}{ Total $(\boldsymbol{n}=\mathbf{9 8 8})$} \\
\hline & Mean Score & SD \\
\hline * Maternal care (score range 10-40) & 33.42 & 5.09 \\
* Paternal care (score range 10-40) & 31.64 & 5.70 \\
* Maternal control (score range 5-20) & 12.36 & 3.15 \\
* Paternal control (score range 5-20) & 11.90 & 3.15 \\
* Maternal allowance of autonomy (score range 5-20) & 13.68 & 3.39 \\
* Paternal allowance of autonomy (score range 5-20) & 13.65 & 3.44 \\
* Parental monitoring (score range 5-20) & 15.30 & 3.79 \\
** Family connectedness (score range 5-25) & 19.91 & 3.86 \\
** Parent-youth communication on sex (score range 5-25) & 7.33 & 3.88 \\
& Yes, f (\%) & No, f (\%) \\
** Family modelling behaviours & $229(23.2)$ & $759(76.8)$ \\
\hline
\end{tabular}

Notes: * Parenting behaviour variables; ** Family interaction variables; $\mathrm{SD}=$ standard deviation, $\mathrm{f}=$ frequency; $\%=$ percentage. All variables were continuous variables except the family modelling behaviours which was a dichotomous variable.

Table 2. Bivariate analysis for family interaction and parenting behaviours for male and female youths.

\begin{tabular}{|c|c|c|c|c|c|}
\hline \multirow{2}{*}{ Parenting and Family Interaction } & \multirow{2}{*}{ Gender } & \multicolumn{2}{|c|}{ According to Gender } & \multirow{2}{*}{$t$-Test } & \multirow{2}{*}{$p$-Value } \\
\hline & & Mean Score & SD & & \\
\hline \multirow{2}{*}{${ }^{*}$ Maternal care (score range $10-40$ ) } & Female $(n=566)$ & 33.69 & 5.146 & \multirow{2}{*}{1.92} & \multirow{2}{*}{0.06} \\
\hline & Male $(n=422)$ & 33.06 & 5.006 & & \\
\hline \multirow{2}{*}{ * Paternal care (score range 10-40) } & Female $(n=566)$ & 31.97 & 5.639 & \multirow[b]{2}{*}{2.07} & \multirow[b]{2}{*}{0.04} \\
\hline & Male $(n=422)$ & 31.21 & 5.758 & & \\
\hline \multirow{2}{*}{ * Maternal control (score range 5-20) } & Female $(n=566)$ & 12.24 & 3.040 & \multirow{2}{*}{1.36} & \multirow{2}{*}{0.17} \\
\hline & Male $(n=422)$ & 12.52 & 3.281 & & \\
\hline \multirow{2}{*}{ * Paternal control (score range 5-20) } & Female $(n=566)$ & 11.96 & 3.108 & \multirow{2}{*}{0.69} & \multirow{2}{*}{0.49} \\
\hline & Male $(n=422)$ & 11.82 & 3.203 & & \\
\hline \multirow{2}{*}{$\begin{array}{l}\text { * Maternal allowance of autonomy } \\
\text { (score range 5-20) }\end{array}$} & Female $(n=566)$ & 13.34 & 3.461 & \multirow{2}{*}{-3.72} & \multirow{2}{*}{$<0.001$} \\
\hline & Male $(n=422)$ & 14.14 & 3.248 & & \\
\hline \multirow{2}{*}{$\begin{array}{l}\text { * Paternal allowance of autonomy } \\
\text { (score range 5-20) }\end{array}$} & Female $(n=566)$ & 13.20 & 3.500 & \multirow{2}{*}{-4.88} & \multirow{2}{*}{$<0.001$} \\
\hline & Male $(n=422)$ & 14.26 & 3.255 & & \\
\hline \multirow{2}{*}{$\begin{array}{l}\text { * Parental monitoring } \\
\text { (score range 5-20) }\end{array}$} & Female $(n=566)$ & 15.90 & 3.587 & \multirow{2}{*}{5.86} & \multirow{2}{*}{$<0.001$} \\
\hline & Male $(n=422)$ & 14.50 & 3.906 & & \\
\hline \multirow{2}{*}{$\begin{array}{l}\text { ** Family connectedness } \\
\text { (score range 5-25) }\end{array}$} & Female $(n=566)$ & 20.30 & 3.873 & \multirow{2}{*}{3.65} & \multirow{2}{*}{$<0.001$} \\
\hline & Male $(n=422)$ & 19.39 & 3.791 & & \\
\hline \multirow{3}{*}{$\begin{array}{l}\text { ** Parent-youth communication on } \\
\text { sex (score range 5-25) }\end{array}$} & Female $(n=566)$ & 7.79 & 4.129 & \multirow{2}{*}{4.39} & \multirow{2}{*}{$<0.001$} \\
\hline & Male $(n=422)$ & 6.71 & 3.432 & & \\
\hline & & Yes, $\mathrm{f}(\%)$ & No, $f(\%)$ & $x^{2}$ & $p$-value \\
\hline \multirow{2}{*}{ ** Family modelling behaviours } & Female $(n=566)$ & $150(26.5)$ & $416(73.5)$ & \multirow{2}{*}{8.22} & \multirow{2}{*}{0.005} \\
\hline & Male $(n=422)$ & $79(18.7)$ & $343(81.3)$ & & \\
\hline
\end{tabular}

Notes: * Parenting behaviour variables; ${ }^{* *}$ Family interaction variables; $\mathrm{SD}=$ standard deviation; $\mathrm{f}=\mathrm{frequency}$; $\%=$ percentage. All variables were continuous variables except the family modelling behaviours which was a dichotomous variable. 
The results suggested that there was a gender difference in sexual intention among the youths. Overall, there were 84 students $(8.5 \%)$ with a mean total score of $\geq 3$ for sexual intention that were classified as having sexual intention. Almost one in five male youths expressed their intention to perform sexual activity $(n=76,18 \%)$ and a smaller number of female youths expressed such sexual intention $(n=8,1.4 \%)$. Table 3 shows the multivariate logistic regression of parenting behaviours and family interaction on the sexual intention of male and female youths. The influence of parenting behaviours and family interaction on youth sexual intention also differed according to gender. In male youths, having frequent parent-youth communication on sex reduced the odds of having sexual intention $(\mathrm{AOR}=0.89,95 \% \mathrm{CI}=0.81-0.99)$ while having high maternal control $(\mathrm{AOR}=1.19$, $95 \% \mathrm{CI}=1.03-1.38)$ and family modelling behaviour (AOR $=2.25,95 \% \mathrm{CI}=1.19-4.25)$ increased the odds of sexual intention. These factors were not significant in female youths. The presence of a high level of family connectedness reduced the odds of having sexual intention ( $\mathrm{AOR}=0.76$, $95 \%$ CI $=0.59-0.97$ ) in females but not in males. Parental care, monitoring, and allowance of autonomy were not significant in determining the sexual intention of male and female youths. Statistically, the full model was significant in predicting sexual intention in male youths $\left(\chi^{2}=22.75, p=0.01\right)$ but not female youths $\left(\chi^{2}=16.52, p=0.09\right)$. Both models were only able to explain (Nagelkerke $\mathrm{R}^{2}$ ) less than $1 \%$ of the variance in sexual intention of male youths and $21 \%$ of the variance in sexual intention of female youths, suggesting that other factors might have influenced youth decision on sexual activity.

Table 3. Logistic regression of family interactions and parenting variables on youth sexual intention for male and female youths.

\begin{tabular}{|c|c|c|c|c|c|c|c|c|}
\hline \multirow[b]{2}{*}{ Parenting and Family Interaction } & \multicolumn{4}{|c|}{ Males $(n=422)$} & \multicolumn{4}{|c|}{ Females $(n=566)$} \\
\hline & B & S.E. & Wald & AOR $(95 \% \mathrm{CI})$ & B & S.E. & Wald & AOR $(95 \% \mathrm{CI})$ \\
\hline Maternal Care & 0.01 & 0.04 & 0.02 & $1.01(0.92-1.10)$ & 0.11 & 0.11 & 1.04 & $1.12(0.90-1.39)$ \\
\hline Maternal Autonomy & 0.03 & 0.08 & 0.11 & $1.03(0.88-1.20)$ & -0.23 & 0.21 & 1.69 & $0.76(0.50-1.15)$ \\
\hline Paternal Care & -0.01 & 0.04 & 0.10 & $0.99(0.92-1.07)$ & -0.01 & 0.10 & 1.12 & $0.90(0.73-1.10)$ \\
\hline Paternal Control & -0.06 & 0.08 & 0.65 & $0.94(0.80-1.09)$ & 0.03 & 0.19 & 0.03 & $1.03(0.71-1.15)$ \\
\hline Parental Monitoring & -0.07 & 0.04 & 3.05 & $0.93(0.85-1.01)$ & 0.09 & 0.12 & 0.53 & $1.09(0.86-1.37)$ \\
\hline Parent-Youth Communication on Sex & -0.11 & 0.05 & 4.50 & $0.90(0.81-0.99)$ * & 0.11 & 0.08 & 1.72 & $1.12(0.95-1.32)$ \\
\hline Family Modelling Behaviour Yes [No] & 0.81 & 0.33 & 6.19 & $2.25(1.19-4.25)$ * & 0.31 & 0.81 & 0.14 & $1.36(0.28-6.72)$ \\
\hline$x^{2}$ & $22.75^{*}$ & & & & 16.52 & & & \\
\hline$R^{2}$ & 0.09 & & & & 0.21 & & & \\
\hline
\end{tabular}

Notes: OB = Beta; S.E = standard error; AOR = adjusted odds ratio; $95 \%$ CI = 95\% confidence interval; $\mathrm{R}^{2}=$ Negelkerke $\mathrm{R}^{2}{ }^{*}=p<0.05$. All variables were continuous variables except the family modelling behaviours which was a dichotomous variable.

\section{Discussion}

This study investigated the gender difference in the family interaction, parenting behaviours, and sexual intention experienced by youths aged 18 to 24 years. The findings of this study supported the hypotheses that gender differences exist in parenting behaviours, family interaction, and youth sexual intention. This study has also shown that the influence of family interaction and parenting behaviours on youth sexual intention varies between male and female youths.

\subsection{Parenting Behaviours, Family Interactions, and Gender Difference}

Mothers were scored higher in the care, control and allowance of autonomy parenting domains than fathers, indicating that mothers played an important role in the youths' upbringing. This pattern is a typical traditional parenting style practiced by Asians in general and Malaysians in particular, where mothers are often the main person involved in child rearing.

As mentioned earlier, authoritarian parenting is a common parenting style practiced by Malaysian parents. However, based on the results of this study, the youths reported to have received a high level of parental care with a moderate level of allowance of autonomy, control, and monitoring. This finding 
indicates a changing trend in the parenting styles of Malaysian parents; our parents are moving away from authoritarian parenting to the authoritative style in which they practice some level of control together with care and warmth. This is further supported by a recent local study conducted among school students aged 14 to 16 years in Selangor, one of the states in Malaysia, which showed that authoritative parenting was the most common parenting behaviour experienced by the youths (Kiadarbandsari et al. 2016). The moderate level of parental control is an expected behaviour, as parents tend to be less controlling in older children (Wang et al. 2011). Furthermore, in the Malaysian context, people above 18 years of age are legally considered as adults and allowed to make their own decisions. However, parents of this study still showed their caring attitudes, and this was evident in the moderate level of parental monitoring reported by the youths. Despite their age, parents monitored and knew their activities when they were not at home.

In terms of gender difference, male youths reported greater freedom, as they received a higher level of allowance of autonomy compared to female youths. They had a lower level of paternal care, family connectedness, and parent-youth communication on sex than the female youths. The low level of parent-youth communication means that there was infrequent discussion on sexual issues between them. This low parent-son communication on sexual issues is similar to that found among Korean youths, in which parents had the tendency to communicate on sexual issues more with their daughters compared to sons (Cha et al. 2007). Both male and female youths in this study experienced a moderate level of parental control. This is in contrast with a local study conducted among college students and a study among Arab youths, in which parents placed less control on their daughters compared to sons (Tam et al. 2012; Dwairy et al. 2006). Male youths are risk takers and tend to involve in riskier activities compared to female youths, thus parents tend to place higher restriction and controlling behaviours on their sons than daughters. Nevertheless, it is enlightening to find from this study that parents placed certain level of control that was not too much or too little regardless of their children's gender. Studies have shown that parents with over-controlling or low controlling behaviours were associated with sexual activity in their children (Coley et al. 2008; Farahani et al. 2011; Wang et al. 2007). The level of parental control needs to be just enough to discipline and cultivate acceptable behaviours in their children. As for family modelling behaviours, more females were aware of their family members' past premarital sexual activity compared to male youths. This could be related to the higher level of family connectedness in female youths compared to male youths, thus making females more aware of their family members' activities.

\subsection{Prevalence of Youths with Sexual Intention and Gender Difference}

The prevalence of youths with sexual intention was low, where 8 in 100 youths expressed their intention to perform sexual activity. The low prevalence of sexual intention among the youths in this study is expected, as premarital sex is not accepted in Malaysia. The proportion of female youths with sexual intention was only $1 \%$, which was 10 times less than what found among female youths in South Africa (Mathews et al. 2009). The prevalence of sexual intention among male youths was 18\%, lower than the prevalence found among male youths in South Africa and Iran (Mathews et al. 2009; Mohtasham et al. 2009). In comparison to other Asian youths, the prevalence of female youths with sexual intention found in this study was similar with the prevalence found among female youths in China. However, our male youths showed higher intention by more than 10 times compared to male youths in China (Zhang and Jemmott 2014). Modernisation and globalisation might have affected Malaysian youths, especially males, to a larger extent compared to Chinese youths.

There were more male youths with the intention to perform sexual activity compared to female youths. This is similar to findings among Asian, South African, and Western youths, in which male youths were found to be more expressive and showed a higher intention not to stay abstinent until their marriage compared to female youths (Leerlooijer et al. 2014; Zhang and Jemmott 2014; Cha et al. 2007; Mathews et al. 2009; Forehand et al. 2005). This male predominant pattern is also related to the societal 
norms in which male youths receive less stigmatisation of premarital sexual activities compared to female youths (Marston and King 2006; Chi et al. 2012).

\subsection{The Influence of Parenting Behaviours and Family Interactions on the Sexual Intention of Male and Female Youths}

In general, there were gender differences in the way family interactions and parenting behaviours influenced youth sexual intention. Higher level of maternal control increased the odds of sexual intention among male youths. Over-controlling mothers may have a negative influence on their sons. Male youths may see the act of mothers placing high control and restriction on them as intruding their life, thus they rebel. They plan and involve themselves in activities that are against their mothers' restrictions and guidance. In contrast, a study in China showed that the absence of parental restriction or guidance, in other words low parental control, would increase the risk of male youths' involvement in premarital sex (Wang et al. 2007). This was further supported by two other studies that showed the positive influence of parental control in reducing the risk of youth sexual activity ( $\mathrm{O}^{\prime}$ Donnell et al. 2008; Parkes et al. 2011). Hence, it is important for future studies to assess the level of parental control that youths perceive as non-intrusive and that will influence them towards positive behaviours, including planning to stay abstinent until marriage.

Awareness of family members' past premarital sexual activity increased the odds of having the intention to practice similar behaviours in male youths. This is consistent with a study conducted among American youths in Rhode Island, which showed that youths who perceived their siblings as being sexually active were likely to have a permissive attitude and be sexually active (Almy et al. 2015). The modelling behaviour by youths was obvious when parents of the same gender displayed such behaviours. For example, in a study that looked into youth alcohol consumption, boys tended to follow their fathers' drinking habit, whereas girls would follow their mothers' drinking habit (Vanassche et al. 2014). However, due to the nature of our data, we were not able to further classify the family modelling behaviours according to parental gender.

Overall, there was a low level of parent-youth communication on sexual issues, significantly lower in males compared to females. However, this study managed to highlight the importance of having such communication. Frequent or high parent-youth communication on sex reduced the odds of having the intention to practice premarital sex in their sons. Based on this positive influence, it is important to highlight to parents the importance of discussing sexual issues with their children, as evidence has shown that parents tend to be biased; they communicated more with their daughters than sons and most communications were done by mothers (Grossman et al. 2015; Gallegos et al. 2007). In addition, a study in Thailand showed that mothers were more likely to talk about the issues only when they think their daughters were sexually active and the discussions were rather superficial, wherein they hardly discussed contraception, HIV/STD infection, or pregnancy (Rhucharoenpornpanich et al. 2012). Malaysia is a conservative country, and discussing personal issues such as sexual activity between parents and children is not a common practice. Similarly, studies conducted in other Asian and Arab countries also showed low parent-youth communication on sexual issues (Chi et al. 2012; Shrestha et al. 2013; Sridawruang et al. 2010; Alquaiz et al. 2012; Farahani et al. 2011). Thus, it is important to educate parents, especially those from conservative cultures, to be more open and ready to talk to their youths, especially sons, on sexual issues. Failing which, their sons or children may learn from others, including peers and social media, putting them at risk of obtaining incorrect and misleading information. The time spent discussing sexual issues such as pregnancy and sexually transmitted diseases will be an opportunity for parents to educate their sons on the importance of practicing safe sex and conforming to social or family values and norms.

Family connectedness implies the closeness, warmth, and support from family members to the youths. It was found that high level of family connectedness reduced the odds of having sexual intention among the female youths. This is consistent with longitudinal data in the US which showed that female youths with a close relationship with their fathers were less likely to engage in sexual 
activity. However, the father-son relationship was not significant in determining the sexual activity of male youths (Regnerus and Luchies 2006). Another study among US youths showed that responsive parenting with regular family activities during early youth was associated with later involvement in premarital sexual activities among youths (Coley et al. 2008). When youths feel close and attach to their families, they are more inclined to follow the family's rule and moral values, which in this context includes not practicing premarital sexual activity. Highly connected youths tend to turn to their family for guidance and emotional support.

Overall, the models of both genders were only able to explain a small variant in the youth sexual intention. Other factors such as peers, social media, or even personal attitudes may have influenced youth sexual intention. Nevertheless, the positive influence of family factors cannot be denied and, hence, improving parenting skills and family interaction may be integrated in intervention programs to reduce risky sexual activities among youths.

A few limitations exist in this study. This study only involved youths in colleges and did not include youths who were working or not studying. Thus, the findings are limited to youths who are mainly students. The prevalence of sexual intention among youths found in this study was low, especially among female youths, and this could be because they may not be truthful enough to declare their true sexual intention, as it is against the societal norms to plan and practice premarital sexual activities. Although they were ensured confidentiality and the questionnaire was anonymous, their true response was still not guaranteed. In addition, the family interactions and parenting behaviours were only based on the youths' perception and the results were limited to this. Perhaps future studies may examine the relationship between family behavioural factors based on parental perspective and their association with youth sexual intention.

In conclusion, this study reveals that although there is a changing trend in parenting styles among Malaysian parents, gender differences still exist. Male youths were allowed higher autonomy and experienced less interaction with their families compared to females. These parenting behaviours indirectly affected youth decision on sexual activities, in which more males than females had expressed their intention to practice premarital sex within the next 12 months. In designing intervention programs that involve family, it is very important to acknowledge that there are gender differences in the influence of family factors on the youth sexual decision-making process. Different parenting approaches need to be used; frequent parent-youth communication on sexual issues and having some level of parental control may reduce male youths' involvement in the activity, while promoting closely connected families may reduce sexual intention in the female youths. This finding is particularly important in populations that share the same values as Malaysia, such as the Arab and Asian countries; in particular, those that do not accept premarital sexual activity. Nevertheless, the positive influence of parent-youth communication on sex, parental control, and having closely connected families on sexuality of youths from countries that accept premarital sexual activity is subject to further investigation.

Acknowledgments: The researchers would like to acknowledge the voluntary participation from the college students and the cooperation from the principals of the participating colleges and the Ministry of Education Malaysia. This study received fundamental research grant from Universiti Kebangsaan Malaysia (FF-2013-328).

Author Contributions: Noor Azimah Muhammad conducted the field work and drafted the manuscript. Khadijah Shamsuddin, Rahmah Mohd Amin and Khairani Omar supervised the project. Hizlinda Tohid was involved in the manuscript writing. All authors read and approved the final manuscript.

Conflicts of Interest: The authors declare no conflict of interest.

\section{References}

Afifi, Tamara D., Andrea Joseph, and Desiree Aldeis. 2008. Why can't we just talk about it? Journal of Adolescent Research 23: 689-721. [CrossRef]

Ahmad, Noor Ani, S. Maria Awaluddin, Hasimah Ismail, Rahama Samad, and Nik Rubiah N. A. Rashid. 2014. Sexual Activity among Malaysian School-Going Adolescents What Are the Risk and Protective Factors? Asia-Pacific Journal of Public Health 26: 44S-52S. [CrossRef] 
Ahmadian, Maryam, Hanina H. Hamsan, Haslinda Abdullah, Asnarulkhadi Abu Samah, and Amna Md Noor. 2014. Risky sexual behavior among rural female adolescents in Malaysia: A limited role of protective factors. Global Journal of Health Science 6: 165-74. [CrossRef] [PubMed]

Ajzen, Icek. 2011. The Theory of Planned Behaviour: Reactions and reflections. Psychology E Health 26: 1113-27. [CrossRef]

Almy, Brandon, Kristin Long, Debra Lobato, Wendy Plante, Barbara Kao, and Christopher Houck. 2015. Perceptions of Siblings' Sexual Activity Predict Sexual Attitudes Among At-Risk Adolescents. Journal of Developmental and Behavioral Pediatric 36: 258-66. [CrossRef] [PubMed]

Alquaiz, Aljoharah M., Maha A. Almuneef, and Hafsa R. Minhas. 2012. Knowledge, attitudes, and resources of sex education among female adolescents in public and private schools in Central Saudi Arabia. Saudi Medical Journal 33: 1001-9. [PubMed]

Anwar, Mudassir, Syed Azhar Syed Sulaiman, Keivan Ahmadi, and Tahir M. Khan. 2010. Awareness of school students on sexually transmitted infections (STIs) and their sexual behavior: A cross-sectional study conducted in Pulau Pinang, Malaysia. BMC Public Health 10: 47. [CrossRef] [PubMed]

Barnes, Horward L., and David H. Olson. 1985. Parent-Adolescent Communication and the Circumplex Model. Child Development 56: 438-47. [CrossRef]

Baumrind, Diana. 2005. Patterns of parental authority and adolescent autonomy. New Directions for Child and Adolescent Development 108: 61-69. [CrossRef]

Blum, Robert W., and Marjorie Ireland. 2004. Reducing risk, increasing protective factors: Findings from the Caribbean Youth Health Survey. Journal of Adolescent Health 35: 493-500. [CrossRef]

Boislard, Marie-Aude, Daphne Bongardt, and Martin Blais. 2016. Sexuality (and Lack Thereof) in Adolescence and Early Adulthood: A Review of the Literature. Behavioral Sciences 6: 8. [CrossRef] [PubMed]

Buhi, Eric R., and Patricia Goodson. 2007. Predictors of adolescent sexual behavior and intention: A theory-guided systematic review. Journal of Adolescent Health 40: 4-21. [CrossRef] [PubMed]

Carmack, Chakema C., and Rhonda K. Lewis-Moss. 2009. Examining the theory of planned behavior applied to condom use: The effect-indicator vs. causal-indicator models. The Journal of Primary Prevention 30: 659-76. [CrossRef] [PubMed]

Cha, Eun S., Willa M. Doswell, Kevin H. Kim, Denise Charron-Prochownik, and Thelma E. Patrick. 2007. Evaluating the theory of planned behavior to explain intention to engage in premarital sex amongst Korean college students: A questionnaire survey. International Journal of Nursing Studies 44: 1147-57. [CrossRef] [PubMed]

Chi, Xinli, Lu Yu, and Sam Winter. 2012. Prevalence and correlates of sexual behaviors among university students: A study in Hefei, China. BMC Public Health 12: 972. [CrossRef] [PubMed]

Coley, Rebekah L., Bethany L. Medeiros, and Holly S. Schindler. 2008. Using Sibling Differences to Estimate Effects of Parenting on Adolescent Sexual Risk Behaviors. Journal of Adolescent Health 43: 133-40. [CrossRef] [PubMed]

Deardorff, Julianna, Jeanne M. Tschann, Elena Flores, and Emily J. Ozer. 2010. Sexual values and risky sexual behaviors among Latino youths. Perspectives on Sexual and Reproductive Health 42: 23-32. [CrossRef] [PubMed]

Deković, Maja, and Kristen L. Buist. 2005. Multiple perspectives within the family. Journal of Family Issues 26: 467-90. [CrossRef]

Department of Statistics Malaysia. 2016. Current Population Estimates, Malaysia, $2014-2016$. Available online: https://www.dosm.gov.my/v1/index.php?r=column/ctheme\&menu_id= L0pheU43NWJwRWVSZklWdzQ4TlhUUT09\&bul_id=OWlxdEVoY1JCS0hUZzJyRUcvZEYxZz09 (accessed on 25 July 2017).

Dwairy, Marwan, Mustafa Achoui, Reda Abouserie, Adnan Farah, Anaya A. Sakhleh, Mona Fayad, and Hassan K. Khan. 2006. Parenting styles in Arab societies: A first cross-regional research study. Journal of Cross-Cultural Psychology 37: 230-47. [CrossRef]

Farahani, Farideh K. A., John Cleland, and Amir H. Mehyar. 2011. Associations between family factors and premarital heterosexual relationships among female college students in Tehran. International Perspectives on Sexual and Reproductive Health 37: 30-39. Available online: http: / www.jstor.org/stable/41202968 (accessed on 30 August 2016). 
Forehand, Rex, Mary Gound, Beth A. Kotchick, Lisa Armistead, Nicholas Long, and Kim S. Miller. 2005. Sexual intentions of black preadolescents: Associations with risk and adaptive behaviors. Perspectives on Sexual and Reproductive Health 37: 13-18. [CrossRef] [PubMed]

Gallegos, Esther C., Antonia M. Villarruel, Marco V. Gómez, Dora J. Onofre, and Yan Zhou. 2007. Research brief: Sexual communication and knowledge among Mexican parents and their adolescent children. The Journal of the Association of Nurses in AIDS Care: JANAC 18: 28-34. Available online: https:/ / doi.org/10.1016/j.jana. 2007.01.007 (accessed on 30 August 2016).

Grossman, Jennifer M., Allison J. Tracy, Amanda M. Richer, and Sumru Erkut. 2015. The Role of Extended Family in Teen Sexual Health. Journal of Adolescent Research 30: 31-56. [CrossRef] [PubMed]

Gullota, Thomas. 2008. How theory influences treatment and prevention practice with the family. In Family Influences on Childhood Behavior and Development. Edited by Thomas P. Gullota and Gary M. Blau. New York: Taylor \& Francis Group, LLC, pp. 1-20. ISBN 978-0-415-96532-3 (0).

Ismayilova, Leyla, Fred M. Ssewamala, and Leyla Karimli. 2012. Family Support as a Mediator of Change in Sexual Risk-Taking Attitudes among Orphaned Adolescents in Rural Uganda. Journal of Adolescent Health 50: 228-35. [CrossRef] [PubMed]

Jozkowski, Kristen. N., and Zoë D. Peterson. 2013. College students and sexual consent: Unique insights. Journal of Sex Research 50: 517-23. [CrossRef] [PubMed]

Keshavarz, Somayeh, and Rozumah Baharudin. 2009. Parenting Style in a Collectivist Culture of Malaysia. European Journal of Social Sciences 10: 66-73.

Kiadarbandsari, A., Z. Madon, H. H. Hamsan, and K. Mehdinezhad Nouri. 2016. Role of Parenting Style and Parents' Education in Positive Youth Development of Adolescents. Pertanika Journal of Social Sciences $\mathcal{E}$ Humanities 24: 1465-80. Available online: http://www.pertanika.upm.edu.my/Pertanika\%20PAPERS/ JSSH\%20Vol.\%2024\%20(4)\%20Dec.\%202016/13\%20JSSH-1432-2015.pdf (accessed on 17 April 2017).

Kotchick, Beth A., Anne Shaffer, Kim S. Miller, and Rex Forehand. 2001. Adolescent sexual risk behavior: A multi-system perspective. Clinical Psychology Review 21: 493-519. [CrossRef]

Lee, Tan Yan, and David P. P. Lok. 2012. Bonding as a positive youth development construct: A conceptual review. The Scientific World Journal 2012: 1-11. [CrossRef] [PubMed]

Leerlooijer, Joanne N, Robert A. C. Ruiter, Rita Damayanti, Liesbeth E. Rijsdijk, Ellen Eiling, Arjan E. R. Bos, and Gerjo Kok. 2014. Psychosocial correlates of the motivation to abstain from sexual intercourse among Indonesian adolescents. Tropical Medicine E International Health 19: 74-82. [CrossRef]

Manaf, Mohd Rizal A., Mastura Mohd Tahir, Hatta Sidi, Marhani Midin, Nik Ruzyanei Nik Jaafar, Srijit Das, and Abdul Muizz Abd Malek. 2014. Pre-marital sex and its predicting factors among Malaysian youths. Comprehensive Psychiatry 55: S82-S88. [CrossRef]

Markham, Christine M., Susan R. Tortolero, S. Liliana Escobar-Chaves, Guy S. Parcel, Ronald Harrist, and Robert C. Addy. 2003. Family connectedness and sexual risk-taking among urban youth attending alternative high schools. Perspectives on Sexual and Reproductive Health 35: 174-79. [CrossRef] [PubMed]

Marston, Cicely, and Eleanor King. 2006. Factors that shape young people's sexual behaviour: A systematic review. Lancet 368: 1581-86. [CrossRef]

Mathews, Catherine, Leif E. Aarø, Alan J. Flisher, Wanjiru Mukoma, Annegreet G. Wubs, and Herman Schaalma. 2009. Predictors of early first sexual intercourse among adolescents in Cape Town, South Africa. Health Education Research 24: 1-10. [CrossRef] [PubMed]

Mohtasham, Ghaffari, Niknami Shamsaddin, Mohsen Bazargan, Kazemnejad Anosheravan, Mirzaee Elaheh, and Ghofranipour Fazlolah. 2009. Correlates of the intention to remain sexually inactive among male adolescents in an Islamic country: Case of the Republic of Iran. The Journal of School Health 79: 123-29. [CrossRef] [PubMed]

Muhammad, Noor Azimah, Khadijah Shamsuddin, Rahmah Mohd Amin, Khairani Omar, and Ramayah Thurasamy. 2017. Questionnaire development and validity to measure sexual intention among youth in Malaysia. BMC Public Health 17: 157. [CrossRef] [PubMed]

Muhammad, Noor Azimah, Khadijah Shamsuddin, Khairani Omar, Shamsul A. Shah, and Rahmah Mohd Amin. 2014. Validation of the Malay Version of the Parental Bonding Instrument among Malaysian Youths Using Exploratory Factor Analysis. Malaysian Journal of Medical Sciences 21: 51-59. [PubMed] 
Murry, Velma M., Ronald L. Simons, Leslie G. Simons, and Frederick X. Gibbons. 2013. Contributions of family environment and parenting processes to sexual risk and substance use of rural African American males: A 4-year longitudinal analysis. The American Journal of Orthopsychiatry 83: 299-309. [CrossRef] [PubMed]

O'Donnell, Lydia, Ann Stueve, Richard Duran, Athi Myint-U, Gail Agronick, Alexi S. Doval, and Renee Wilson-Simmons. 2008. Parenting Practices, Parents' Underestimation of Daughters' Risks, and Alcohol and Sexual Behaviors of Urban Girls. Journal of Adolescent Health 42: 496-502. [CrossRef] [PubMed]

Parker, Gordon, Hilary Tupling, and L. B. Brown. 1979. A parental bonding instrument. British Journal of Medical Psychology 52: 1-10. [CrossRef]

Parkes, Alison, Marion Henderson, Daniel Wight, and Catherine Nixon. 2011. Is Parenting Associated with Teenagers' Early Sexual Risk-Taking, Autonomy and Relationship with Sexual Partners? Perspectives on Sexual and Reproductive Health 43: 30-40. [CrossRef] [PubMed]

Regnerus, Mark D., and Laura B. Luchies. 2006. The Parent-Child Relationship and Opportunities for Adolescents' First Sex. Journal of Family Issues 27: 159-83. [CrossRef]

Rhucharoenpornpanich, Orratai, Aphichat Chamratrithirong, Warunee Fongkaew, Brenda A. Miller, Pamela K. Cupp, Michael J. Rosati, Hilary F. Byrnes, Katherine A. Atwood, and Warunee Chookhare. 2012. Parent-teen communication about sex in urban Thai families. Journal of Health Communication 17: 380-96. [CrossRef] [PubMed]

Rodgers, Kathleen B., and Jenifer K. McGuire. 2012. Adolescent Sexual Risk and Multiple Contexts: Interpersonal Violence, Parenting, and Poverty. Journal of Interpersonal Violence 27: 2091-107. [CrossRef] [PubMed]

Sales, Jessica M., Robin R. Milhausen, Gina M. Wingood, Ralph J. DiClemente, Laura F. Salazar, and Richard A. Crosby. 2008. Validation of a parent-adolescent communication scale for use in STD/HIV prevention interventions. Health Education \& Behavior 35: 332-45. [CrossRef]

Sallis, James F., Neville Owen, and Edwin B. Fisher. 2008. Ecological Models of Health Behavior. In Health Behavior and Health Education: Theory, Research, and Practice, 4th ed. Edited by Karen Glanz, Barbara K. Rimer and K. Viswanath. San Francisco: Jossey-Bass Inc Pub, pp. 465-85.

Sacolo, Hlengiwe N., Min-Huey Chung, H. Hsin Chu, Yuan-Mei Liao, Chiung-Hua Chen, Keng-Lian Ou, Lu-I Chang, and Kui-Ru Chou. 2013. High risk sexual behaviors for HIV among the in-school youth in Swaziland: A Structural Equation Modeling approach. PLoS ONE 8: e67289. [CrossRef]

Shrestha, Rachana M., Keiko Otsuka, Krishna C. Poudel, Junko Yasuoka, Medin Lamichhane, and Masamine Jimba. 2013. Better learning in schools to improve attitudes toward abstinence and intentions for safer sex among adolescents in urban Nepal. BMC Public Health 13: 244. [CrossRef] [PubMed]

Siebold, Carmel. 2011. Factors influencing young women's sexual and reproductive health. Contemporary Nurse 37: 124-36. [CrossRef] [PubMed]

Sridawruang, Chaweewan, Michael Pfeil, and Kenda Crozier. 2010. Why Thai parents do not discuss sex with their children: A qualitative study. Nursing $\mathcal{E}$ Health Sciences 12: 437-43.

Steinberg, Laurence. 2014. Families in Adolescence, 10th ed. New York: McGraw Hill, pp. 119-49.

Tam, Cai-Lian, Teck-Heang Lee, Vashnarekha Kumarasuriar, and Wai-Mun Har. 2012. Parental Authority, Parent-child Relationship and Gender Differences: A study of college students in the Malaysian Context. Australian Journal of Basic and Applied Sciences 6: 182-89.

Vanassche, Sofie, An Katrien Sodermans, Koen Matthijs, and Gray Swicegood. 2014. The effects of family type, family relationships and parental role models on delinquency and alcohol use among Flemish adolescents. Journal of Child and Family Studies 23: 128-43.

Villarruel, Antonia M., John B. Jemmott, Loretta S. Jemmott, and David L. Ronis. 2004. Predictors of sexual intercourse and condom use intentions among Spanish-dominant Latino youth: A test of the Planned Behavior Theory. Nursing Research 53: 172-81. [CrossRef] [PubMed]

Vuttanont, Uraiwan, Trisha Greenhalgh, Mark Griffin, and Petra Boynton. 2006. "Smart boys" and "sweet girls"-sex education needs in Thai teenagers: A mixed-method study. Lancet 368: 2068-80. [CrossRef]

Wang, Bo, Xiaoming Li, Bonita Stanton, Vafa Kamali, Sylvie Naar-King, Iqbal Shah, and Ronald Thomas. 2007. Sexual attitudes, pattern of communication, and sexual behavior among unmarried out-of-school youth in China. BMC Public Health 7: 189. [CrossRef] [PubMed]

Wang, Ming Te, Thomas J. Dishion, Elizabeth A. Stormshak, and John B. Willett. 2011. Trajectories of family management practices and early adolescent behavioral outcomes. Developmental Psychology 47: 1324-41. [CrossRef] [PubMed] 
Zhang, Jingwen, and John B. Jemmott. 2014. Unintentional exposure to online sexual content and sexual behavior intentions among college students in China. Asia-Pacific Journal of Public Health 27. [CrossRef] [PubMed]

Zuo, Xiayun, Chaohua Lou, Ersheng Gao, Yang Cheng, Hongfeng Niu, and Laurie S. Zabin. 2012. Gender differences in adolescent premarital sexual permissiveness in three Asian cities: Effects of gender-role attitudes. Journal of Adolescent Health 50: S18-S25. [CrossRef] [PubMed] 